\title{
OS NOVOS MONUMENTOS DAS METRÓPOLES
}

\author{
Ricardo Ohtake \\ Arquiteto, Curador da $5^{a}$ Bienal Internacional de Arquitetura de São Paulo. \\ Secretário Municipal da Cultura de São Paulo - 1993-94
}

\begin{abstract}
Resumo: Análise das relações entre a construção de grandes equipamentos culturais, especialmente museus, e o sentido do desenvolvimento das metrópoles. O artigo apresenta uma tipologia dessas relações, detendo-se em casos de Washington, Paris, Tóquio, São Paulo e Rio de Janeiro, entre outros.

Palavras-chave: museus e impactos urbanos; economia e cultura; metrópoles e serviços culturais.
\end{abstract}

$\mathrm{C}$ omo desdobramento da implantação dos museus nas principais cidades européias a partir do final do século XVIII, constata-se que nos últimos 20 anos os equipamentos culturais, principalmente museus, passam a ganhar significado nos grandes centros urbanos. Essa onda cultural recente faz surgir novas especificidades que estão vinculadas a diversos fatores, entre os quais destacam-se tanto a circunscrita rearticulação urbana, quanto a amplitude propiciada pela globalização da atual fase capitalista.

Diversas sociedades e suas metrópoles respondem diferentemente a essa nova onda de instalação de equipamentos culturais e tal tendência vem sendo seguida não apenas pelas metrópoles internacionais, vinculadas aos pólos dinâmicos da economia que passam a ter nos seus equipamentos culturais atrações nucleares para o avanço do setor de serviço, mas também pelas metrópoles dos países em desenvolvimento.

Assim, diferentes práticas internacionais estão sendo experimentadas por diversos países, muitas vezes configurando modelos que se legitimam internamente e se expandem para além das suas fronteiras. De imediato, pode ser lembrado o caso do Japão, cujas experiências na implantação de equipamentos culturais circunscreve um modelo no qual os recursos públicos foram a principal fonte para a construção de equipamentos nacionais, metropolitanos, provinciais e municipais. Nesse país a me- trópole é compreendida no interior de um sistema nacional e a política metropolitana é estabelecida dentro de uma visão global do país.

Os modelos de implantação desses equipamentos, adotados por americanos e europeus, caracterizam-se pela presença simultânea da iniciativa privada e do poder público num esforço conjunto para transformar a metrópole em um local de atração do grande público para os eventos culturais. Guardando algumas particularidades, Paris formula uma estratégia de construção de vultosos equipamentos culturais, visando um desenvolvimento desejado e planejado da metrópole com o intuito da revitalização urbana.

O Brasil, que conheceu a construção dos seus primeiros museus somente no século XIX, desde então edificava esses equipamentos tendo como referência os padrões europeus. Atualmente as cidades de São Paulo e Rio de Janeiro, pela posição do país no sistema internacional, ainda continuam importando fórmulas e modelos originados ou nos Estados Unidos ou na Europa, e cada uma dessas cidades guardam especificidades que lhe imprimem particulares dimensões culturais: o Rio de Janeiro deixase marcar como a cidade do poder político institucionalizado e São Paulo como a cidade da força da iniciativa privada, dada por um empresariado dinâmico. Os palácios do Rio do século XIX até a década de 30 estão sendo remodelados para a cultura, a fim de dar ao centro o movimento e a dignidade da história da cidade; em São Paulo 
espalham-se equipamentos pela cidade, com o critério de atender ao mercado, criando-se locais para a atração da classe média de maior sofisticação.

No entanto, qualquer desses modelos considera e fundamenta-se nos novos monumentos que, nos últimos vinte anos, as metrópoles de todo o mundo e até as menores cidades dos países mais desenvolvidos estão construindo, numa demonstração de pujança e riqueza do país. Esses novos monumentos são expressões do poder da cultura que, por sua vez, torna-se cada vez mais demonstração do poder e influência de uma nação.

\section{OS PRINCÍPIOS CULTURAIS DE UMA NOVA ERA}

No Brasil, os últimos 30 anos apresentaram uma extraordinária mudança no desenvolvimento urbano, tanto que, a cidade de São Paulo até o começo dos anos 70 tinha, Penha, Lapa, Santana e Santo Amaro como os limites que a classe média então conhecia. Os bairros, além desses, eram aqueles que já se identificavam como extremamente pobres e pensava-se que lá estavam na condição de provisórios, para futuramente serem demolidos e construídas novas locações seguindo os mesmos padrões já incorporados para a expansão urbana original.

Tal otimismo nessa transitoriedade para melhores condições correspondia à época caracterizada pelo "milagre brasileiro", que pregava o crescimento do bolo para depois poder dividi-lo melhor, orientação seguida pelos condutores governamentais da economia, em sintonia com o capital internacional e parte do empresariado nacional. Mas, também, uma década antes, havia se disseminado que o país estava a caminho de maior igualdade, e a construção de Brasília, no final da década de 50, preconizava essa situação de esperança.

Entretanto, ao se verificar no transcurso do tempo o crescimento urbano da cidade de São Paulo, tanto essa esperança desenvolvimentista como a racionalidade propiciada pelo regime militar não impediriam que o avanço urbano da cidade se fizesse superando ou eliminando as carências habitacionais que já existiam, e continuam a existir, em torno da central mancha urbana da cidade. São Paulo levou 400 anos para formar uma estrutura urbana que deixaria habitar populações carentes ao seu redor, mesmo que às vezes em pequena proporção. O paradoxo é aqueles limites e problemas criados em quatro séculos não serem reduzidos, mas multiplicados: nesses últimos 30 anos a cidade dobrou de tamanho, sem ampliar proporcionalmente os recursos habitacionais e as condições de trabalho para sua população.
Da perspectiva internacional, alguns fatores potencializavam as dificuldades urbanas. A crise do petróleo, que culminou em 1973, também auxiliou a inversão daquelas esperanças e expectativas citadas anteriormente, ao repassar para os países subdesenvolvidos o custo alto do petróleo, a alta dos preços dos produtos industrializados e a queda dos preços das matérias-primas.

Se tais fatores indicam algumas das insuficiências enfrentadas pelo desenvolvimento urbano no Brasil (e de forma geral, nos países subdesenvolvidos), de certa maneira e sob outros contextos eles irão auxiliar no avanço econômico dos países ricos. Em poucos anos o desequilíbrio entre as nações tornou-se tão acentuado que se fez sentir também no nível das aglomerações urbanas, imprimindo um novo sentido ao crescimento das cidades do bloco dos países ricos, que passam a investir grandes cifras nos seus centros urbanos até chegar a privilegiar construções de inusitados espaços culturais.

Somente para marcar com exatidão esse momento de intensivo investimento no setor cultural, pode ser citado o caso da nova ala da National Gallery de Washington, o primeiro daquela faixa de museus nacionais da capital americana. José Neistein, o crítico de arte que dirige há mais de 30 anos o Brazilian American Cultural Institute, numa conferência em São Paulo, dizia que essa construção era possivelmente a última grande obra da humanidade com finalidade cultural. Essa nova ala foi construída ao lado do prédio neoclássico do museu e lhe faz um total contraponto, pois é de vidro, lembrando a pirâmide do Louvre, do mesmo arquiteto, I.M.Pei. O custo da nova obra, inaugurada em 1975, chegou a 96 milhões de dólares - o maior gasto até então destinado a uma construção na área da cultura.

A última grande obra cultural da humanidade? Realmente anos se passaram, até que um país, que já perdera a hegemonia cultural, surge com um projeto ousado, o Centro Georges Pompidou, no platô decadente de Beaubourg, em Paris, com um projeto dentro da volumetria da cidade e ocupando metade da quadra, abrindo uma praça na outra metade. As fachadas, totalmente de vidro, chocaram a população pelas tubulações aparentes dos serviços da edificação e da escada rolante unindo os andares.

A new wing da National Gallery de Washington foi realmente a última realização de uma fase de construção de equipamentos como os museus e o Centro Pompidou, a primeira de uma nova etapa da história cultural. A crise do petróleo de 1973 foi um marco na separação da natureza e do tipo de construções de museus no mundo inteiro. A partir da abertura do Pompidou em 1981, são trans- 
corridos 20 anos em que os equipamentos culturais passam a tornar-se o termômetro do desenvolvimento de uma cidade ou de uma nação.

Ainda no caso da França, Paris construiu nessas duas décadas vários equipamentos culturais de vultosas dimensões: a nova Ópera, a nova Biblioteca Nacional, a ampliação do Museu do Louvre, o restauro e a adaptação do Museu d'Orsay e ainda alguns equipamentos menores como o Instituto do Mundo Árabe e o Espaço Cartier de Arte Contemporânea, algo em torno de 5 bilhões de dólares, nesses 20 anos.

Os 96 milhões da National Gallery são um valor irrisório diante das atuais cifras dos novos museus construídos no mundo. O Centro Pompidou foi projeto vencedor em um concurso nacional, de autoria do italiano Renzo Piano e do inglês Richard Rogers. É um espaço de porte até hoje inigualável: dois andares para a biblioteca, um para o acervo do Museu Nacional de Arte Moderna (MNAM) e um para exposições temporárias, além de espaços menores como o pequeno teatro de múltiplo uso, o cinema, as salas de exposições temporárias de arte contemporânea, os espaços para as crianças, etc.

A biblioteca trouxe uma novidade que outras grandes bibliotecas não tinham ousado: self-service (livre acesso), que tornou a biblioteca extremamente ágil, pois o leitor consulta qualquer livro e revista para saber quais levará para a mesa de leitura. $\mathrm{O}$ espaço em que se misturam estantes de livros e mesas é muito estimulante, eliminando a frieza das grandes bibliotecas e suas infindáveis salas de leitura, espaços pouco convidativos para a leitura e também para estar.

Com o acervo do MNAM incorporado ao Centro Pompidou, foi possível recontar a arte moderna, uma fase de extraordinária beleza e de muita diversidade, o que torna a mostra instigante e um convite para os olhos.

Tal a freqüência ao Centro nesses 20 anos, que ele atingiu o limite de suas possibilidades de atendimento - tanto na capacidade física como na de serviços. Uma das medidas tomadas para evitar o excesso de lotação foi a instalação de um contador automático para controlar o fluxo de visitantes. O período da manhã foi reservado inicialmente para a reposição dos livros nas estantes e limpeza. Posteriormente esse trabalho passou a ser feito de madrugada para que o público pudesse freqüentá-lo desde cedo. Em 1997, o Centro foi fechado para reforma, ampliação e adaptação de espaços, ficando assim durante mais de dois anos, voltando a ser aberto em 2000.

O Centro Pompidou pode ser considerado o primeiro espaço cultural de grande porte do novo período econô- mico do mundo e provavelmente o de maior sucesso de público e excelência de atividades. Além do mais, não se conhece outro espaço desse porte que seja multidisciplinar, característica cada vez mais importante quando se considera a eficiência de funcionamento dos museus ou centros de cultura.

Essa tendência das novas construções amplia-se de tal forma que as edificações culturais construídas nas últimas décadas passam a incorporar o caráter do espetacular, porque são levantadas em países favorecidos pela nova transferência de riqueza. É exatamente esse poder econômico que vai financiar a construção de teatros, óperas, museus, bibliotecas, arquivos, como nunca as cidades e metrópoles conheceram até então.

Toda essa somatória de recursos naturais reforçam ainda mais os países do capitalismo avançado no conjunto das relações internacionais, facilitando ou impondo divulgações de seus artistas, das suas produções culturais e até de suas diretrizes políticas para a área da cultura. Estados Unidos e França podem ser lembrados como os dois grandes exemplos desse fenômeno, recentemente seguidos pela Espanha e Inglaterra. Por sua vez, pode-se sugerir, a ausência desses recursos culturais, ou sua incipiência, indica o pequeno papel do Brasil no cenário internacional e as dificuldades do país para divulgar e exportar a arte brasileira e políticas culturais nacionais.

Retomando o caso de Paris, fica clara a perfeita harmonia dos interesses nacionais e culturais com a rearticulação da escala urbana da capital francesa. Nessa metrópole, as novas construções foram locadas em áreas onde a revitalização era totalmente necessária, um projeto urbano e cultural, portanto, de pleno sucesso.

Entretanto, esse interesse pelo urbanismo não foi o mesmo em outras metrópoles ou cidades, como Tóquio, Nova York e, inclusive, São Paulo. O que ocorreu nessas três cidades, por exemplo, foi a construção na escala urbana, visando a revitalização das áreas ou bairros, mas apenas com a aplicação de altíssimas cifras como forma de expressar um poderio econômico.

Nesse sentido, principalmente dos anos 80 em diante, tem início um período em que não se fala mais na cultura como prioridade, mas da cultura como grande vitrine do desenvolvimento e da riqueza das nações mais poderosas.

No meio desse processo e, sem dúvida, motivo de enriquecimento dos fortes países capitalistas, houve a fragorosa derrota da União Soviética e seu desaparecimento, o que proporcionou hegemonia mundial ao sistema capitalista, acentuando ainda mais a extraordinária pujança 
de países como os Estados Unidos, França, Alemanha, Inglaterra e até novos no grupo, como a Espanha.

Nesse grupo de países, destaca-se o Japão, uma nação que continua a se preocupar com a manutenção das tradições culturais e passa a investir pesadamente em equipamentos culturais.

\section{JAPÃO - PROLIFERAÇÃO CULTURAL}

Num país como o Japão, algo em torno de 300 museus foram construídos nos anos 80 e 90 , fazendo parte do projeto japonês erguer três tipos: o primeiro, o museu de arte, modelo conhecido, que tem por objetivo desenvolver a sensibilidade da população; o segundo, o histórico, para aprofundar o espírito de cidadania, uma vez que abrange a história do local que pode ser o bairro, a pequena cidade, a região ou a grande cidade; o terceiro, o museu de ciência que aproxima o público dos pequenos experimentos, das conquistas humanas e possibilita maior familiaridade às novas tecnologias, ao mesmo tempo que pretende aguçar a curiosidade dos jovens para as profissões técnicas, pois a procura universitária está se dirigindo para a área de administração e negócios e o desenvolvimento do país passa pela formação de físicos e engenheiros.

Exemplo de pequena cidade, Tokushima é uma das quatro províncias da ilha de Shikoku. Apesar de a província ter 800 mil habitantes e a cidade 280 mil, diariamente sai um avião de grande porte (250 lugares) para Tóquio, pela manhã, que volta no final da tarde, além de vôos para outras localidades.

No final da década de 80 , ainda no Japão, foi planejada a construção de cinco unidades culturais: o arquivo de documentos oficiais, a biblioteca, o museu de arte, o museu histórico e a casa do futuro. Custo do empreendimento: 350 milhões de dólares. Nenhuma dessas unidades tem paralelo no Brasil, não no tamanho, mas na qualidade.

Os espaços de exposições do museu ficam numa penumbra e as obras perfeitamente iluminadas como se não houvesse a fonte de luz; as esculturas e as instalações recebem iluminação especial para cada obra. A construção desse museu serve para que a província comece a ter sua coleção - e o faz por pequenos Picassos, impressionistas e outros mestres do século XX, gravuras da pop americana, de japoneses que pintaram a região de Tokushima e outras obras disponíveis nos mercados mundial e japonês a preços compatíveis com o orçamento. O cuidado com o espaço para guardar o acervo se faz com paredes de madeira tratada para evitar umidade e insetos, ao mesmo tempo que permite respiração ao espaço.
$\mathrm{O}$ arquivo de documentos oficiais e a biblioteca não apresentam maiores novidades, como os espaços muito bem estudados para haver eficiência e utilização agradável, desde o tamanho dos espaços até os materiais adequados. O pavilhão do futuro ainda é uma pequena amostra do que poderá vir a ser, tendo em vista a automação, as comunicações e todas as novas tecnologias que estão sendo colocadas à disposição do público.

O museu histórico apresenta um modelo que se repete em vários outros museus do gênero no país. Mostra as eras geológicas de formação da ilha de Shikoku, com a vegetação de cada era, o aparecimento dos animais e os primeiros homens com seus povoamentos. Na seqüência, mostra a história do homem, os primitivos ajuntamentos, a agricultura, a cidade, os meios de locomoção, o comércio grande e o diário, aspectos da vida privada.

Tudo isso em diferentes séculos, até chegar aos dias atuais. $\mathrm{O}$ espectador presencia a história por diferentes linguagens. Pelas maquetes é possível visualizar uma paisagem de 200 a 500 metros do que é importante, como a organização social de um ajuntamento, mas não interessa, nessa maquete, definir como é, por exemplo, a vegetação. Os desenhos proporcionam grandes visuais de quilômetros ou detalhes. Reproduções tridimensionais em escala natural de moradias, como a pré-histórica, outra sobre árvore ou de uma família do século XVII; da oficina de trabalho de um artesão na cidade; do bosque que existia na região, com a vegetação reproduzida magistralmente. Vídeos e filmes se espalham por todo o museu e objetos de diversas épocas, em geral recolhidos pela população e doados ao museu, como gráficos, tabelas, textos, fotografias a partir de uma certa época, depoimentos e música.

A ordem cronológica permite aos visitantes entender excepcionalmente a formação da cidade e da província em que vive, como foi a vida dos seus antepassados e como as gerações se desenvolveram até hoje, sua organização social, sua cultura.

Embora seja uma pequena província, Tokushima ampliou a visão cultural da população. Dentro de um projeto global, pode-se imaginar a reprodução desse modelo em cada província e cidade, até chegar à metrópole e a um sistema nacional.

\section{TÓQUIO - MULTIPLICAÇÃO DE MUSEUS}

O modelo museológico metropolitano de Tóquio (Museu Edo-Tokyo) é o maior em informações e em cultura 
material, multiplicado na escala de uma das maiores metrópoles do mundo.

Esse museu levou quase uma década para ser aberto ao público e consumiu algo como 550 milhões de dólares, quase a metade com o terreno.

Edo é a antiga denominação da cidade, mudada em função da modernização do Japão e da sua transformação em nova capital, Tóquio, na década de 1870 .

No museu existe uma estupenda entrada com a réplica em escala 1:2, ou seja, a metade do tamanho original, da principal ponte de Tóquio, Nihonbashi. Em cada lado da ponte há uma edificação: de um lado, um teatro da época de Edo, onde se representa o kabuki, tradicional teatro japonês que fala muito do dia-a-dia; do outro, a sede de um periódico diário da época de Tóquio, já em estilo arquitetônico ocidental. São duas edificações que mostram formas diferentes de comunicação, um teatro e um jornal, cada uma de sua época.

A partir daí, segue o modelo de outros museus históricos do Japão do final do século XX, porém com a desenvoltura correspondente à escala da capital japonesa.

$\mathrm{Na}$ Grande Tóquio, esses museus se multiplicam com modelos semelhantes e todos contam com a participação da população, na coleção de objetos, fotografias, depoimentos e documentos. Eles têm escalas compatíveis com sua localização, regiões que fazem parte da metrópole, como Guarulhos, Mogi das Cruzes, Osasco, etc, regiões da Grande São Paulo, antigos povoados autônomos que com o crescimento urbano se juntaram a Tóquio.

Apesar de a população japonesa ter espírito coletivo, nos últimos tempos, com o extraordinário desenvolvimento capitalista, o individualismo começou a se impor e daí a preocupação governamental em criar os museus históricos, para levantar a questão da cidadania e realçar o espírito coletivo.

Mais um museu metropolitano, o Museu de Arte Contemporânea, é totalmente adequado para a produção artística atual, com salas de pé-direito de 5 metros e duas com quase 20 metros, usadas quando o artista faz um projeto especial. Esse empreendimento custou algo cerca de 550 milhões de dólares, incluindo o terreno e uma parte da aquisição de obras. É um museu que coloca Tóquio dentro do circuito mundial das grandes exposições contemporâneas, tendo sido construído para isso.

Entre os museus do sistema nacional, o Museu Etnológico, em Osaka, foi construído na grande área em que se localizou a Expô de 1970, já fora da cidade. Os três pavilhões do museu, que indicam seu grande porte, abrigam objetos de uso do povo com desenhos específicos de cada população, do mundo todo. A cada período de um a três anos, um encarregado pela coleta e análise de objetos de um país percorre diversas localidades, mesmo as já visitadas. É um museu que acumula, com seu trabalho, um conhecimento profundo da humanidade. Entre seus pesquisadores, em 1995, havia 65 doutores! Do Brasil, há mais de cinco mil objetos, de instrumentos indígenas a fantasias de destaques dos últimos desfiles de Escolas de Samba.

Outro museu de muito interesse, o Museu Nacional da História do Japão, localizado na zona rural, a meio caminho entre Tóquio e o aeroporto de Narita, traça a história de outra forma: pelos acontecimentos e representações da história política, com documentos, desenhos, obras de arte, jornais, fotografias, reproduções de espaços, maquetes, e desenvolvimento de pesquisa científica de alto nível utilizando a tecnologia de forma sofisticada.

De um pedaço de tábua, por exemplo, aparentemente sem interesse, sob um aparelho de leitura de raios ultravioletas, surge uma escrita, após decodificação por computador no vídeo de um monitor, de uma antiga placa que os paleontólogos do museu decifram. Esse museu também tem em seu quadro pesquisadores e doutores em grande número.

O museu faz questão de salientar a participação popular no desenho político da nação e enriquecer a função urbana, desencadeando atos como o dos zengakuren, na década de 60 , e as manifestações visuais não essencialmente políticas da década de 90 , entre outros.

Um grande número de museus dessas duas décadas tem avançados projetos de arquitetura, a maior parte de arquitetos japoneses, mas vários também de estrangeiros.

Esses museus são de iniciativa de governos metropolitanos, provinciais e municipais, portanto todos governamentais. No entanto, a iniciativa privada tem inúmeros empreendimentos, como o Museu Suntory, em Osaka, o Museu Asahi, nos arredores de Kyoto, famosos por terem o projeto arquitetônico de Tadao Ando, e muitos outros, como o complexo arquitetônico privado na cidade de Fukuoka, caminho entre Tóquio e Nagoya, terceira cidade do Japão, que tem como principal ocupante o Hotel Okura, em Tóquio, um dos principais e mais luxuosos. Dentro desse conjunto, além de todos os equipamentos hoteleiros, existem salas e auditórios para reuniões empresariais e sociais e um auditório de música erudita para 1.200 espectadores, especialmente projetado para som acústico, onde qualquer ruído no palco se propaga para toda a platéia. Ao lado, há outro auditório para música 
popular com som amplificado para 2.500 espectadores. No início, essas salas não eram muito usadas, mas em pouco tempo passaram a ter utilização constante e completa.

O Japão, que sofreu um abalo econômico em 1997 e desde o início dos anos 90 apresentava queda na sua vertiginosa evolução que se iniciou na década de 70 , foi possivelmente o país que mais investiu em equipamentos culturais no novo período de riqueza que caracterizou os países desenvolvidos desde a crise do petróleo.

Conseguiu traçar um plano para atingir toda a população do país com projetos de abrangência geral, como os que têm o país inteiro nas suas ações, até chegar por um sistema de capilaridade a projetos locais. Nesse plano, a metrópole adquire maior visibilidade porque é uma questão nova, com abordagem nova, um universo novo de público.

\section{MUSEUS - UMA CONSTELAÇÃO INTERNACIONAL}

Não só no Japão, mas nos Estados Unidos e Europa, grandes inversões foram feitas na cultura. Na Europa: reforma na National Gallery de Londres, a Tate e a Tate Modern, Victoria \& Albert Museum, inúmeros museus na Alemanha, a ampliação e a adequação do Louvre, a sede de museus nas províncias francesas, adaptações dos museus de Berlim, a construção do Museu Judaico, a Galeria Nazionale de Roma, o Reina Sofia e o Thyssen Bornemisza em Madrid, a reforma do Prado, o Centro Cultural de Belém e a criação e reforma de dezenas de museus em Lisboa, os museus de arte contemporânea do Porto, de Santiago de Compostela e de Barcelona. E muitos outros, especialmente o Guggenheim de Bilbao.

Nos Estados Unidos, foram construídos ou reformados os maiores museus: reforma do MoMA - Museum of Modern Art de Nova York (indo agora para a segunda), Getty de Los Angeles que até hoje está com problemas de funcionamento, o Museu do Halocausto em Washington, e o futuro Guggenheim ao sul de Manhattan, além de dezenas de outros.

Um dos primeiros museus de arte que não tem receio de revelar seu lado comercial é o Museu Guggenheim, com suas próprias exposições e outras casas que abre em diferentes cidades, como já vinha fazendo timidamente em Berlim, Soho e Veneza, e mais recentemente o fez com toda a desenvoltura em Bilbao e tenta reproduzir o modelo em Manhattan e na América do Sul, e uma das fortes candidatas é a cidade do Rio de Janeiro.
O elevar ao máximo o uso do acervo do museu e das exposições realizadas em Nova York, Quinta Avenida, preenche as programações de todas as casas. No entanto, são as casas que pagam as contas, principalmente com a participação da comunidade, entendida como os governos locais (municipais, regionais, centrais) e a iniciativa privada por meio de patrocínios. Os patrocínios têm o retorno de marketing e as contribuições governamentais, benefícios para a comunidade, como transporte de pessoas para a cidade, hotéis, restaurantes, transporte urbano, venda de objetos turísticos, e todas as outras conseqüências de novos negócios de comércio e serviço. Em Bilbao, por exemplo, está sendo construído um grande teatro para reter o turista por mais uma noite, além do aumento de atividades do pavilhão de feiras da cidade.

O Museu Guggenheim no Brasil, cuja construção ainda não está acertada, carregará consigo um complexo hoteleiro de espaços de convenções e escritórios comerciais. Dessa forma, a globalização na área de museus começa a acontecer de uma forma extremamente mais ousada, complexa e diferente do desenvolvimento de museus como o MoMA, por exemplo, que construiu apartamentos em cima do próprio museu, para gerar recursos para novas construções e sua manutenção. Apesar de essa operação ter sido realizada há uma década, já se desenvolve uma outra, com a compra de um prédio contíguo e nova reforma da atual edificação.

O Guggenheim deixa de lado também aspectos que os puristas, os curadores tradicionais e áreas significativas das artes têm total ojeriza, por exemplo algumas exposições como a de motocicletas e a de Armani, ambas tidas por eles como excessivamente comerciais e, por outros, consideradas mostras que abrem o museu para um público que nunca o freqüentaria.

De qualquer forma, se há dez anos ou pouco mais, os museus como o MoMA, o Exploratorium - museu de ciência de San Francisco -, e o próprio Louvre iniciaram processos heterodoxos para melhoramento de suas instalações e sua manutenção, e já se estranhava a operação, com a economia extremamente modificada se espera que o processo adotado pelo Guggenheim seja mais um passo.

O processo europeu tem um componente extremamente interessante em alguns casos, como o novo equipamento cultural valorizar determinada área para atrair investimentos imobiliários na região. Não é novidade, pois anteriormente isso já havia acontecido com o Lincoln Center em Nova York, para revigorar a área a oeste do Central Park. 


\section{CULTURA E REARTICULAÇÃO URBANAS}

No caso de Paris, a situação é muito clara. Inicialmente foi o bairro de Beaubourg que teve no Centro Georges Pompidou o indutor de uma recuperação que se deu não só no aspecto físico das edificações, como na qualificação das residências e do comércio.

A seguir, o Museu Picasso, no Marais, abriu o processo de renovação no bairro e, finalmente, a Ópera da Bastilha completou a grande área da cidade e em pouco mais de dez anos recuperou centenas de edificações que desde a Idade Média ocupam essa grande região central de Paris.

Posteriormente, foi construída a Biblioteca Nacional da França na margem esquerda do Sena, região que se deteriorou muito e começa a se recuperar lentamente. Afinal, a Biblioteca entrou em funcionamento somente em 1997.

Essa forma de associar a construção de equipamentos culturais com o desenvolvimento urbano é extremamente interessante, mas exige equipamentos de tamanho compatível com a movimentação urbana e força suficiente da economia da cidade para que esse fenômeno acompanhe $\mathrm{o}$ indutor.

Não é apenas necessário o investimento cultural governamental que, aliás, no Lincoln Center, foi privado. Mas é importantíssimo que a iniciativa particular, os donos dos imóveis individuais ou condomínios queiram participar desse restauro ou fazer investimentos novos. Isso dependerá do mercado querer novas moradias, de que se estabeleça um comércio renovado e outras funções compatíveis venham participar da nova função urbana.

É um processo muito lento e muitas vezes doloroso, pois expulsa, dentro do jogo capitalista, ocupantes que estão há muito tempo no bairro e não conseguem sobreviver a essa situação nova, embora a lentidão da transformação diminua muito essa dificuldade de alguns.

O processo japonês, um projeto nacional em que foram investidas dezenas de bilhões de dólares, está baseado nos recursos governamentais.

O processo europeu também é baseado no investimento governamental, mas foi um processo misto no caso do Louvre, no qual há espaços para lojas e cuja ocupação permite reverter recursos para a manutenção do museu.

No caso americano, é grande a procura por museus, na maioria particulares, que possam ter formas alternativas para pagar a manutenção e o investimento nas atividades-fim.
No entanto, na Europa e nos Estados Unidos, provavelmente hoje todos os museus governamentais (como os da Smithsonian Institution) ou particulares procuram patrocínio das empresas.

\section{REDES CULTURAIS E NOVAS FEIÇÕES DAS METRÓPOLES BRASILEIRAS}

No Brasil, o caso é semelhante. Os museus particulares ou governamentais necessitam, cada vez mais, da participação da iniciativa privada. Se, há poucos anos, o governo ainda participava de diversas iniciativas, hoje mal consegue pagar a manutenção básica. Como os patrocínios sustentam as mostras de maior visibilidade, as atividades de pesquisa profunda ou a manutenção de acervo têm dificuldade de recursos. Para tanto, as fundações e entidades de apoio cultural têm participado desse trabalho, mas a procura de entidades estrangeiras é praticamente nula.

No Rio de Janeiro, houve um processo de recuperação do centro ligado à abertura e revitalização de uma série de antigos edifícios da administração:

- a antiga casa real, o Paço Imperial, tornou-se um local de exposições muito ativo, ligado ao governo federal;

- a antiga alfândega se tornou a Casa França-Brasil para historiar e continuar a conexão com a cultura francesa, que tanto influenciou os costumes e o pensamento brasileiros, é uma casa de exposições ligada ao governo estadual;

- o antigo edifício que serviu de sede de serviços postais, a Empresa Brasileira de Correios e Telégrafos, tornou-se também um local de exposições da própria empresa, ligada ao governo federal;

- o Centro Cultural Hélio Oiticica do governo municipal, local de exposições para guardar a memória do artista e expor obras de outros artistas com quem tem parentesco na linha de trabalho;

- e finalmente, o Centro Cultural Banco do Brasil, o mais ativo espaço cultural no país, transformou uma antiga agência em um conjunto onde são feitas exposições de artes plásticas, peças de teatro, dança, manifestações de música, conferências, etc, com uma destinação de verba que nunca um espaço cultural obtivera.

É interessante verificar, também, o esforço para a recuperação da Fundação Progresso pela iniciativa privada, o Circo Voador e outras entidades, que há mais de uma década conseguem realizar atividades, mas não recuperar a edificação. Reabilitar o centro do Rio é um pensamento 
antigo que teve diversos projetos: Rio Centro, Corredor Cultural, Rio Arte, mas a sua execução efetiva é dos anos 90, com o amadurecimento da idéia de que a cultura é um bom indutor para a recuperação de áreas urbanas deterioradas. Evidentemente, a ação não se esgota aí. É necessário que muito investimento seja feito para que os bens particulares também sejam revalorizados, que as empresas voltem a fazer negócios no centro, que haja população para a demanda de serviços e, principalmente, que sejam retomadas e reocupadas as habitações.

São Paulo, nas primeiras décadas do século XX, teve poucos equipamentos culturais de porte, como a Pinacoteca do Estado e o Teatro Municipal. Na metade desse século, a Biblioteca Mario de Andrade, o conjunto do Parque Ibirapuera, o Teatro de Cultura Artística. Na segunda metade, o MASP - Museu de Arte de São Paulo, o Centro Cultural São Paulo, o Sesc Pompéia.

Na última década do século, o novo Museu Paulista, a nova Pinacoteca, a Sala São Paulo, o Teatro Alfa, os equipamentos do Sesc e a nova Oca do Parque Ibirapuera, espaço para grandes exposições, como foi concebido em sua criação no IV Centenário da cidade. Assim, São Paulo foi aperfeiçoando muito lentamente os locais de apresentação da arte, e museus com acervos importantes são somente a Pinacoteca, o MASP e o MAC - Museu de Arte Contemporânea da Universidade de São Paulo.

A Luz é um bairro antigo da cidade, hoje extremamente decaído. Há um grande esforço para sua recuperação e, neste caso, a transformação das grandes edificações em espaços culturais é o que está dando uma nova característica ao bairro. Há 130 anos, o traçado do trem cortou os seus campos e a estação chamou-se da Luz, em homenagem à santa, em frente ao Parque da Luz, dentro do qual foi construído o Liceu de Artes e Ofícios, que depois veio a ser a Pinacoteca do Estado e cuja recuperação levou décadas. Da mesma forma, a estação vizinha e bem mais recente, a Júlio Prestes, teve o seu grande salão e o jardim transformados na Sala São Paulo de concertos musicais. $\mathrm{O}$ antigo escritório da companhia de estradas de ferro tornou-se o DOPS - Departamento de Ordem Política e Social, órgão policial que prendeu inúmeros militantes e simpatizantes de esquerda e, durante a ditadura militar, foi um dos centros de interrogação, tortura e prisão dos que eram contrários à situação. Esse prédio foi desocupado e hoje aguarda um novo uso. O Museu de Arte Sacra ocupou o Convento da Luz. Os antigos prédios da Escola Politécnica que abrigam repartições do patrimônio histórico municipal, ainda espera melhor ocupação. O Parque da
Luz sofreu total restauração em anos recentes, retomando todo seu esplendor paisagístico e recuperando as obras arquitetônicas: o coreto, a casa de chá, o circuito das águas com todas as suas obras de arte e "instalações", tornando então possível a incorporação da Pinacoteca ao Parque.

Essa recuperação do bairro da Luz é um trabalho que há muito se "planejava", mas só teve início efetivo em 1993, com a Pinacoteca, e a realização desse trabalho contou sempre com a iniciativa estatal. O bairro conta com um vizinho pujante, o Bom Retiro, que teve uma ocupação populacional curiosa, passando dos imigrantes italianos para os judeus e agora coreanos, manejando um fortíssimo negócio industrial e comercial de roupas. Do outro lado da linha férrea, porém, localiza-se a cracolândia, uma das mais tristes áreas da cidade, construída de lojas comerciais, hotéis, bares e boates onde prostitutas, viciados e comerciantes de drogas se misturam a fregueses de baixíssimas posses.

A atividade cultural é um componente que se configura cada vez mais importante para a transformação da região, mas uma intervenção na cracolândia é o que permitirá sua transformação em novo e salutar bairro na cidade, mais interessante se for mantida a atual feição e retomada a característica residencial, juntamente com os serviços e negócios.

No início do novo século, prevê-se a abertura de novos espaços culturais em São Paulo, como o Instituto Tomie Ohtake, em 2001, espaço multidisciplinar de artes visuais e artes cênicas, o MAC na Água Branca, o MAM no pavilhão Prodam do Parque Ibirapuera, o teatro do Parque Ibirapuera, previsto desde o projeto original. Essas e outras edificações com finalidade cultural se localizam nos bairros de classe média da cidade, de modo geral, se espalhando cada vez mais de acordo com a expansão das áreas de habitação e de negócios que envolvem mais dinheiro.

Essas edificações culturais, comparadas com as de países ricos, apesar do grande aperfeiçoamento que obtiveram, ainda não conseguem atingir o mesmo nível de qualidade. Em termos urbanísticos, diferentemente de Paris, onde os grandes equipamentos atraem a população e a nova ocupação da cidade para si, São Paulo vai atrás do público potencial. Exemplo maior é o MAM que instalou salas em shopping-centers, cujo público é essencialmente consumista, assim mesmo faz um esforço para atraí-lo.

Nos últimos anos, aumentou muito o número de espectadores das exposições, tornando necessária a reapresentação de mostras que levem e aumentem efetivamente o público. 
A mídia é fundamental, mas também a forma de apresentação das exposições. A mostra dos "500 Anos" foi uma lição, com as cenografias que deram um contexto às obras. A falta delas deixou de auxiliar no entendimento da arte. Se o site specific é uma modalidade para mostrar a obra num determinado meio, a cenografia ajuda a mostrar o meio que produziu a obra. Esse esforço, juntamente com a mídia, uma questão perseguida por todos, faz uma mostra entrar mais facilmente e com abrangência no interesse geral.

Cresceu também o número de livros sobre arte, que num certo sentido é a grande memória. A arte burguesa e a arte dos museus, entretanto, necessitam da presença e do aumento do número de suas obras no acervo dos museus, o que tem acontecido com pouca freqüência no Brasil.

A arte já faz parte da cultura da metrópole, seja $\mathrm{Pa}$ ris, Tóquio ou São Paulo, e participa cada vez mais da vida dos habitantes, seja para desenvolver a sensibilidade, visitar um museu da vizinhança (lazer), fazer um programa na cidade visitada (turismo) ou para aumentar o conhecimento. No século XXI, nas metrópoles, a atividade cultural, pelo caminho que está trilhando, fará uma nova multidão de espectadores, talvez espectadores-autores. 